\title{
Assessment of Disease Activity in Large-vessel Vasculitis: Results of an International Delphi Exercise
}

\author{
Sibel Z. Aydin, Haner Direskeneli, and Peter A. Merkel, on behalf of the International Delphi on \\ Disease Activity Assessment in Large-vessel Vasculitis
}

\begin{abstract}
Objective. To arrive at consensus for candidate outcomes for disease activity assessment in largevessel vasculitis (LVV) in clinical trials.

Methods. A Delphi survey including 99 items was circulated among international experts for 3 rounds. Results. Fifty-seven items were accepted for both giant cell arteritis and Takayasu arteritis. Sixty-seven percent of experts voted to have a common approach for both diseases with additional disease-specific items such as weight loss, scalp tenderness/necrosis, morning stiffness, dizziness, visual symptoms, and imaging.

Conclusion. This study highlights similarities and differences in experts' perspectives for assessing clinical activity in LVV and may guide a consensus-driven core set of validated outcomes. (First Release September 1 2017; J Rheumatol 2017;44:1928-32; doi:10.3899/jrheum.161269)
\end{abstract}

Key Indexing Terms:

VASCULITIS

TAKAYASU ARTERITIS

GIANT CELL ARTERITIS

LARGE VESSEL

OUTCOMES

Large-vessel vasculitis (LVV) is a rare disease mainly affecting the aorta and its primary branches ${ }^{1,2,3}$. LVV usually has a relapsing-remitting course leading to prolonged periods of seemingly "clinically inactive" disease during which arterial damage can still progress. In clinical practice, physicians managing cases of LVV combine subjective clinical data with fairly unreliable laboratory markers and imaging. A comprehensive review of the literature demonstrated that not only are there no widely accepted or standardized outcome tools in LVV, but also there are not even broadly accepted definitions of important outcomes such as "disease activity" or "response to therapy"."

From the Division of Rheumatology, The Ottawa Hospital Research Institute, University of Ottawa, Ottawa, Ontario, Canada; Division of Rheumatology, Marmara University Faculty of Medicine, Istanbul, Turkey; Division of Rheumatology, and Department of Biostatistics, Epidemiology, and Informatics, University of Pennsylvania, Philadelphia, Pennsylvania, USA.

Sponsored by the Vasculitis Clinical Research Consortium, which has received support from the US National Institute of Arthritis and Musculoskeletal and Skin Diseases (U54 AR057319 and U01 AR51874 04), the National Center for Research Resources (U54 RR019497), and the Office of Rare Diseases Research. Additional support for the work of the OMERACT Vasculitis Working Group was received through a Patient-Centered Outcomes Research Institute Pilot Project Grant. S.Z. Aydin, MD, Associate Professor, Division of Rheumatology, The Ottawa Hospital Research Institute, University of Ottawa; H. Direskeneli, MD, Professor of Rheumatology, Division of Rheumatology, Marmara University Faculty of Medicine; P.A. Merkel, MD, MPH, Professor of Medicine and Epidemiology, Division of Rheumatology, and Department of Biostatistics, Epidemiology, and Informatics, University of Pennsylvania. Address correspondence to Dr. P.A. Merkel, Section of Rheumatology, University of Pennsylvania, White Building, 5th Floor Penn, 3400 Spruce St., Philadelphia, Pennsylvania 19104,USA.E-mail: pmerkel@upenn.edu Accepted for publication June 3, 2017.
The OMERACT Vasculitis Working Group is advancing a research agenda that includes parallel projects to understand the perspectives and insight into outcomes of importance in LVV of (1) experienced physicians and investigators, and (2) patients ${ }^{4}$. An international Delphi exercise was conducted to identify items considered important when determining active disease status in LVV in clinical trials. Specifically, the Delphi aimed to determine (1) experts' consensus opinions on the disease domains/subdomains of importance to study in LVV, and (2) a preliminary set of outcomes and outcome instruments to use to identify key data on the domains. The ultimate goal of our project was to establish a core set of domains and validated outcome measures for use in clinical research in LVV. It has been argued that the 2 major types of LVV, giant cell arteritis (GCA) and Takayasu arteritis (TA), may not be distinct entities, but are part of a single disease spectrum $^{5,6}$. Thus, the Delphi process also aimed to determine whether clinicians feel one common outcome measure could be used to assess disease activity in both GCA and TA.

\section{MATERIALS AND METHODS}

The Delphi survey was sent by e-mail to 317 experts in LVV who are involved in clinical research in vasculitis and/or attended academic vasculitis meetings (Appendix 1). Particular attention was paid to ensure inclusion of different geographic areas and medical specialties. Information was collected regarding participants' practice setting, specialty, country, and level of experience, measured by the number of cases they followed in their career with GCA and TA.

The following question was asked for multiple proposed items in the survey: "Should the following item be used to assess disease activity in TA/GCA in clinical trials?" The participants voted for GCA and TA separately. The first round included 99 items on a 5-point scale (strongly

Personal non-commercial use only. The Journal of Rheumatology Copyright @ 2017 . All rights reserved. 
disagree, disagree, neutral, agree, and strongly agree), in addition to the option of saying "don't know." Items were chosen with the aim of being initially comprehensive, including items from published disease activity assessment tools [Birmingham Vasculitis Activity Score (BVAS), Indian Takayasu Arteritis Score (ITAS), Disease Extension Index in TA] or used by prior clinical investigations ${ }^{4,7,8,9}$ (Supplementary Table 1, available with the online version of this article). Participants were given the option to give feedback and suggest other items in the first round. The 104 comments received from the participants were discussed by all investigators (SZA, HD, PAM) and it was decided that 7 items would be added in the subsequent rounds. Items accepted or rejected by $>70 \%$ of voters were not advanced to subsequent rounds. Sixty-two items were voted for GCA and 63 for TA in the second round and 24 items for GCA and 28 items for TA were voted in Round 3 . The voting results of the participants who had seen $>10$ cases (in each subtype of LVV) in their career were also analyzed and compared to the result of the less experienced participants.

\section{RESULTS}

The first, second, and third rounds were completed by 148 , 111, and 108 participants from 23 countries, respectively. Experts represented multiple relevant medical specialties [rheumatology, $(n=75)$, internal medicine $(n=5)$, cardiology $(n=1)$ vascular surgery $(n=4)$, nephrology $(n=8)$, pediatric rheumatology $(n=6)$, ophthalmology $(n=5)$, and radiology $(n=4)]$. The primary setting of the participants was academic (93\%), and $61 \%$ had been working for more than 10 years.

Ninety-six participants had seen $>10$ cases of GCA and 84 participants had seen $>10$ cases of TA in their life; the results from these more experienced participants were carried through to the final round.

Items commonly accepted for both GCA and TA. Fifty-seven items were accepted for both GCA and TA. These items covered a wide range of manifestations (Table 1 and Table 2).

Items excluded for both GCA and TA. Many items were excluded for both diseases, including anorexia, arthritis, von Willebrand factor antigen, leukocyte count, fibrinogen levels, edema, pyoderma gangrenosum, digital ulcers, oral ulcers, gangrene, erythema nodosum, cardiomyopathy, bloody diarrhea, seizures, organic brain syndrome, dementia, peripheral and cranial neuropathy, psychosis, photophobia, respiratory findings and renal findings (other than rise in blood pressure). Among patient-reported outcomes, the Nottingham Health Profile, EQ-5D, and the Health Assessment Questionnaire (HAQ) were excluded. The physician-based assessments BVAS and ITAS were excluded for both diseases. Within imaging findings, only arterial wall enhancement was not accepted for both forms of vasculitis.

Items accepted only for GCA or TA. Items differently endorsed for GCA or TA are listed in Table 3.

"Can/should we develop 1 common outcome measure for TA and GCA?" Sixty-seven percent of experts voted for a common approach for GCA and TA, but also endorsed development of additional disease-specific instruments; $11 \%$ agreed with aiming to develop 1 set of outcome measures for both GCA and TA (without any modifications for GCA and
Table 1. Candidate outcome measures elements commonly accepted for both giant cell arteritis and Takayasu arteritis.

\begin{tabular}{|c|c|}
\hline Category/Organ System & Specific Candidate Element \\
\hline Constitutional & $\begin{array}{l}\text { Fever }>38^{\circ} \mathrm{C} \\
\text { Fatigue }\end{array}$ \\
\hline Laboratory abnormalities & $\begin{array}{c}\text { Erythrocyte sedimentation rate } \\
\text { C-reactive protein } \\
\text { Hemoglobin/hematocrit }\end{array}$ \\
\hline Vascular items & $\begin{array}{c}\text { New bruit(s) } \\
\text { New loss of pulse(s) } \\
\text { New diminished pulse(s) } \\
\text { Asymmetric blood pressure measurement } \\
\text { Pulse inequality } \\
\text { Extremity claudication }\end{array}$ \\
\hline Gastrointestinal & Abdominal pain (vasculitic) \\
\hline Musculoskeletal & $\begin{array}{l}\text { Arthralgia } \\
\text { Myalgia }\end{array}$ \\
\hline Patient-reported outcomes & $\begin{array}{l}\text { A general health-related outcome measure } \\
\text { SF-36 (all components) } \\
\text { Patient pain assessment } \\
\text { Patient's global assessment } \\
\text { Fatigue measurement instrument }\end{array}$ \\
\hline Imaging* & $\begin{array}{c}\text { CT angiography, PET-CT, MR angiography, } \\
\text { ultrasound }\end{array}$ \\
\hline Cardiovascular & $\begin{array}{c}\text { Carotidynia } \\
\text { Extremity hypoperfusion/threatened limb } \\
\text { Chest pain: pericardial or angina } \\
\text { New hypertension } \\
\text { her symptom attributed to vascular insufficiency }\end{array}$ \\
\hline Renal & Rise in blood pressure (systolic/diastolic) \\
\hline Ocular & $\begin{array}{c}\text { Temporary vision loss (amaurosis fugax) } \\
\text { Blurred vision } \\
\text { Retinal vasculitis (thrombosis or aneurysm) } \\
\text { New permanent visual loss }\end{array}$ \\
\hline Neurological & $\begin{array}{c}\text { Transient ischemic episodes } \\
\text { Syncope } \\
\text { Stroke } \\
\text { New/worsened headache } \\
\text { Hemiparesis, paraparesis }\end{array}$ \\
\hline $\begin{array}{l}\text { Physician-based assessments } \\
\text { N }\end{array}$ & $\begin{array}{l}\text { Physician's global assessment } \\
\text { Relapse (general definition) } \\
\text { Vasculitis Damage Index } \\
\text { Increase in glucocorticoid dose } \\
\text { New/increased immunosuppressive medication } \\
\text { DEI.Tak }\end{array}$ \\
\hline
\end{tabular}

*Different abnormalities on different imaging modalities were voted on separately. SF-36: Medical Outcomes Study Short Form-36; CT: computerized tomography; PET: positron emission tomography; MR: magnetic resonance; DEI.Tak: disease extent index for Takayasu arteritis.

TA); and $22 \%$ said that the 2 diseases were unsuitable for common outcome measures.

Differences between experienced and inexperienced investigators. There were many similarities among both the experienced and inexperienced groups. The differences for GCA were that interleukin 6 (IL-6) levels, dizziness, cranial neuropathy, HAQ, and a rise in creatinine were items considered important only according to the inexperienced participants, whereas fever, hemoglobin/hematocrit, cardiovascular (CV)

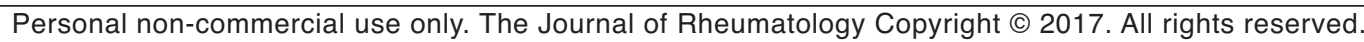


Table 2. Imaging findings by different modalities accepted as potential measures of disease activity for both giant cell arteritis and Takayasu arteritis.

\begin{tabular}{ll}
\hline Modality & Findings \\
\hline CT angiography & Arterial stenosis \\
& Aneurysm \\
& Arterial wall thickening \\
& Arterial wall enhancement \\
& Total uptake values \\
PET-CT & Individual artery update values \\
& Relative uptake compared to liver \\
& Arterial stenosis \\
MR angiography & Aneurysm \\
& Arterial wall thickening \\
& Arterial wall enhancement \\
& Arterial stenosis \\
Aneurysm \\
Altrasound
\end{tabular}

CT: computerized tomography; PET: positron emission tomography; MR: magnetic resonance.

Table 3. Items accepted for only 1 form of large-vessel vasculitis.

\begin{tabular}{lc}
\hline Variables & Details \\
\hline $\begin{array}{l}\text { Giant cell arteritis } \\
\text { Constitutional } \\
\text { Cutaneous }\end{array}$ & Weight loss \\
Susculoskeletal & Scalp necrosis \\
Ocular & Morning stiffness \\
& Scotoma \\
Imaging & Diplopia \\
Takayasu arteritis & Vascular ultrasound: halo sign* \\
Imaging & \\
& Conventional catheter-based angiography \\
Conventional catheter: stenosis
\end{tabular}

\footnotetext{
* Vascular halo sign was only circulated in the first round because of a technical error. It was accepted for giant cell arteritis, but not for Takayasu arteritis.
}

items including new bruits, loss of pulse or inequality, carotidynia, stroke, hemiparesis, and Vasculitis Damage Index were items accepted only by the experienced participants. Inexperienced participants accepted only TA, IL-6, weight loss, European quality of life index, HAQ, and rise in creatinine. Experienced investigators accepted only arthralgia, myalgia, blurred vision, syncope, worsening in headache, and hemiparesis.

\section{DISCUSSION}

The results of this Delphi exercise may help future studies in outlining the range of candidate elements and subdomains to consider when advancing the development of outcome measures of disease activity in LVV in clinical trials. The items that were endorsed include manifestations from the $\mathrm{CV}$, renal, gastrointestinal (GI), nervous, ocular, and musculoskeletal systems. The exclusion of the genitourinary and respiratory systems is consistent with previous publications in which these systems are not sites of LVV-related disease activity ${ }^{10}$. Not all the assessments of specific systems had the same "weight of importance" according to the experts. There was only 1 item in the GI (abdominal vasculitic pain) and renal (rise in blood pressure) sections that was accepted, whereas $\mathrm{CV}$ and nervous systems had markedly more items retained, as expected.

The results of this Delphi study demonstrate that most experts in the management of LVV agree that a large number of items for disease assessment in LVV were suitable for use in both GCA and TA, and that development of a common approach for disease assessment in both diseases would be appropriate. However, a set of additional disease-specific instruments for each disease was also recommended, with the potential to create 1 disease activity assessment tool for LVV, with minor modifications or supplemental measures for each type of LVV.

Our study has several strengths, including the wide variation of the experts regarding specialty and geographic site because physicians from 8 specialties and 23 countries on 4 continents contributed. Large cohorts of patients with LVV have demonstrated that there are variations among different ethnicities in terms of frequencies of disease characteristics for LVV. Therefore, the efforts to include a broad range of experts enhances the generalizability and reliability of these findings. However, about $90 \%$ of participants were from North America or Europe, providing a somewhat unbalanced international representation. This imbalance is also seen for the specialties, despite efforts to distribute the Delphi study to multiple specialties. Additionally, the vast majority of the participants were rheumatologists. Therefore, the results mostly reflect the perspectives of rheumatologists, indicative of how the care of patients with LVV is distributed across different specialties. Further, only some elements were evaluated by some specialists to ensure expertise was matched with a corresponding clinical aspect of disease. Another strength of our study was inclusion of an extensive list of different manifestations in the first round to allow for the wide group of experts to consider all reasonable options for disease assessment.

There are also potential limitations of our study to consider, including the definition of an expert in LVV being defined as having seen at least 10 patients with GCA or TA in their career. This number may be considered too low, especially compared to more prevalent diseases. However, because LVV are rare diseases, drawing the threshold for "expert" from a higher number would significantly reduce the number of investigators able to participate; notably, all participants had participated in prior activities within the

Personal non-commercial use only. The Journal of Rheumatology Copyright @ 2017 . All rights reserved. 
vasculitis research community. In addition, the exclusion of some participants from the analysis is not a common approach for Delphi exercises; however, because a Delphi should only be performed by experts in the area, we took this additional step. Because of the epidemiological differences in LVV, an expert in GCA may not necessarily be experienced in TA and vice versa. Therefore, we limited the analysis to participants who were experienced in that area only, to increase the credibility of the results. This approach was planned as part of the analysis plan prior to the first round of the Delphi being initiated. Another limitation is the lack of a subset definition for "isolated aortitis"11; disease activity in this group of patients might require additional approaches to activity assessment.

Our study identified a set of important items to measure in a clinical trial in LVV, but all items are not required to be included in an activity index. There are many items and overlap among some proposed items; a data-driven statistical approach to item reduction will be necessary.

This Delphi exercise was an important step in achieving expert consensus opinion on items necessary to identify disease activity in LVV and these results will guide future work in outcome measure development in LVV. Further studies are planned to determine a core set of activity domains for use in clinical trials of GCA and TA.

\section{ONLINE SUPPLEMENT}

Supplementary material accompanies the online version of this article.

\section{REFERENCES}

1. Salvarani C, Gabriel SE, O'Fallon WM, Hunder GG. The incidence of giant cell arteritis in Olmsted County, Minnesota: apparent fluctuations in a cyclic pattern. Ann Intern Med 1995;123:192-4.

2. Pamuk ON, Donmez S, Karahan B, Pamuk GE, Cakir N. Giant cell arteritis and polymyalgia rheumatica in northwestern Turkey: Clinical features and epidemiological data. Clin Exp Rheumatol 2009;27:830-3.

3. Watts R, Al-Taiar A, Mooney J, Scott D, Macgregor A. The epidemiology of Takayasu arteritis in the UK. Rheumatology 2009;48:1008-11.

4. Direskeneli H, Aydin SZ, Kermani TA, Matteson EL, Boers M, Herlyn K, et al. Development of outcome measures for large-vessel vasculitis for use in clinical trials: opportunities, challenges, and research agenda. J Rheumatol 2011;38:1471-9.

5. Maksimowicz-McKinnon K, Clark TM, Hoffman GS. Takayasu arteritis and giant cell arteritis: a spectrum within the same disease? Medicine 2009;88:221-6.

6. Grayson PC, Maksimowicz-McKinnon K, Clark TM, Tomasson G, Cuthbertson D, Carette S, et al; Vasculitis Clinical Research Consortium. Distribution of arterial lesions in Takayasu's arteritis and giant cell arteritis. Ann Rheum Dis 2012;71:1329-34.

7. Luqmani RA, Bacon PA, Moots RJ, Janssen BA, Pall A, Emery P, et al. Birmingham Vasculitis Activity Score (BVAS) in systemic necrotizing vasculitis. QJM 1994;87:671-8.

8. Aydin SZ, Yilmaz N, Akar S, Aksu K, Kamali S, Yucel E, et al. Assessment of disease activity and progression in Takayasu's arteritis with Disease Extent Index-Takayasu. Rheumatology 2010;49:1889-93.

9. Misra R, Danda D, Rajappa SM, Ghosh A, Gupta R, Mahendranath $\mathrm{KM}$, et al. Development and initial validation of the Indian
Takayasu Clinical Activity Score (ITAS2010). Rheumatology 2013;52:1795-801.

10. Bicakcigil M, Aksu K, Kamali S, Ozbalkan Z, Ates A, Karadag O, et al. Takayasu's arteritis in Turkey - clinical and angiographic features of 248 patients. Clin Exp Rheumatol 2009;27 Suppl 52:S59-64.

11. Miller DV, Isotalo PA, Weyand CM, Edwards WD, Aubry MC, Tazelaar HD. Surgical pathology of noninfectious ascending aortitis: a study of 45 cases with emphasis on an isolated variant. Am J Surg Pathol 2006;30:1150-8.

\section{APPENDIX 1.}

List of study collaborators (in alphabetical order of the countries): International Delphi on Disease Activity Assessment in Large-vessel Vasculitis: Sergio Toloza, Hospital San Juan Bautista, Catamarca, Argentina; Daniel Blockmans, University Hospital Gasthuisberg, Belgium; Emilia Inoue Sato, Federal University of São Paulo, Brazil; Alexandre Wagner Silva de Souza, Universidade Federal de São Paulo, Brazil; David Cabral, British Columbia Children's Hospital, Canada; Simon Carette, Mount Sinai Hospital-University Health Network, Canada; Leilani Famorca, McMaster University, Canada; Nader Khalidi, McMaster University, Canada; Nataliya Milman, Ottawa Hospital, Canada; Elaine Yacyshyn, University of Alberta, Canada; Vladimir Tesar, Charles University Hospital, Czech Republic; Bo Baslund, Rigshospitalet, Copenhagen, Denmark; Mikkel Faurschou, Copenhagen University Hospital Rigshospitalet, Denmark; Loïc Guillevin, Hôpital Cochin, Paris University, France; Xavier Puéchal, Cochin Hospital, Paris Descartes University, France; Peer Aries, Rheumatologie im Struenseehaus, Germany; Hospital Schleswig-Holstein, Germany; Bernhard Hellmich, Kreiskliniken Esslingen, Germany; Karen Herlyn, University of Schleswig-Holstein, Germany; Julia Holle, University Hospital of Schleswig-Holstein, Germany; Peter Lamprecht, University of Luebeck, Germany; Frank Moosig, Klinikum Bad Bramstedt, Germany; Thomas Neumann, Jena University Hospital, Germany; Jochen Zwerina, University of Erlangen-Nuremberg, Germany; Gunnar Tómasson, University of Iceland, Iceland; Pradeep Bambery, Post Graduate Institute of Medical Education and Research/Bundaberg Hospital, India/Australia; Ramesh Jois, Fortis Hospital, India; Liza Rajasekhar, Nizam's Institute of Medical Sciences, India; Aman Sharma, Postgraduate Institute of Medical Education and Research, India; Rajappa Sivakumar, Cerebrovascular and Vasculitis Research Foundation, India; Eamonn Molloy, St. Vincent's University Hospital, Dublin, Ireland; Philip Hashkes, Shaare Zedek Medical Center, Israel; Fausta Catapano, Sant'Orsola Malpighi of Bologna, Italy; Luca Cimino, Arcispedale Santa Maria Nuova, Reggio Emilia, Italy; Alessandro de Fanti, Arcispedale Santa Maria Nuova, Reggio Emilia, Italy; Nicolo Pipitone, Arcispedale Santa Maria Nuova, Reggio Emilia, Italy; Carlo Salvarani, Arcispedale Santa Maria Nuova, Reggio Emilia, Italy; Augusto Vaglio, University Hospital of Parma, Italy; Shigeto Kobayashi, Juntendo Koshigaya Hospital, Japan; Kazuo Suzuki, Teikyo University, Japan; Luis Felipe Flores-Suárez, Instituto Nacional de Enfermedades Respiratorias, Mexico; Andrea Hinojosa-Azaola, Instituto Nacional de Ciencias Médicas y Nutrición Salvador Zubirán, Mexico; Elisabeth Brouwer, University Medical Center Groningen, the Netherlands; Abraham Rutgers, University Medical Center Groningen, the Netherlands; Coen Stegeman, University Medical Center Groningen, The Netherlands; Ravi Suppiah, Auckland District Health Board and Counties Manukau District Health Board, New Zealand; Ivana Hollan, Lillehammer Hospital for Rheumatic Diseases, Norway; Pedro Arguis, Hospital Clinic of Barcelona, Spain; Maria C. Cid, Hospital Clinic of Barcelona, Spain; Thomas Daikeler, University Hospital Basel, Switzerland; Fatma Alibaz-Oner, Marmara University, Turkey; Vedat Hamuryudan, Istanbul University, Turkey; Gulen Hatemi, Istanbul University, Turkey; Tuncay Hazirolan, Hacettepe University, Turkey; Murat Inanc, Istanbul University, Turkey; Muge Bicakcigil Kalayci, Yeditepe University, Turkey; Sevil Kamali, Istanbul University, Turkey; Tulay Kansu, Hacettepe Üniversitesi Tıp Fakültesi, Turkey; Yaşar Karaaslan, Ankara Numune Education and Research Hospital, Turkey; Omer Karadag, Hacettepe University Faculty of Medicine, Turkey; Gokhan Keser, Ege University School of Medicine,

Personal non-commercial use only. The Journal of Rheumatology Copyright @ $\odot 2017$. All rights reserved 
Turkey; Ahmet Mesut Onat, Gaziantep University, Turkey; Zeynep Ozbalkan, Ankara Numune Research and Training Hospital, Turkey; Seza Ozen, Hacettepe University, Turkey; Hüseyin TE Ozer, Çukurova University, Turkey; Ömer Nuri Pamuk, Trakya University, Turkey; Suzan Guven Yilmaz, Ege University, Turkey; Neil Basu, University of Aberdeen, UK; Alina Casian, Addenbrooke's Hospital, UK; Kuntal Chakravarty, Barking, Havering and Redbridge University Hospitals NHS Trust, UK; David D’Cruz, St. Thomas' Hospital, London, UK; Clive Edelsten, Ipswich Hospital, UK; Lorraine Harper, University of Birmingham, UK; David Jayne, Addenbrookes Hospital, UK; Jeremy Levy, Imperial College Healthcare NHS Trust, UK; Justin Mason, Imperial College London, UK; Joanna Robson, Oxford University, UK; David Scott, Norwich Medical School, UK; Miles Stanford, St. Thomas' Hospital, UK; Richard Watts, Ipswich Hospital, UK; Daniel Albert, Dartmouth-Hitchcock Medical Center, USA; Naomi Amudala, Boston University, USA; Joshua Beckman, Brigham and Women's Hospital,
USA; Marcus Both, University; Billy Chacko, Wake Forest University, USA; Sharon Chung, University of California, San Francisco, USA; Barri Fessler, University of Alabama at Birmingham, USA; Alexandra Giardino, University of Pennsylvania, USA; Peter Grayson, Boston University, USA; Gene Hunder, Mayo Clinic, USA; Carol Langford, Cleveland Clinic, USA; Melissa Lerman, The Children's Hospital of Philadelphia, USA; Kimberly Liang, University of Pittsburgh, USA; Harold Litt, University of Pennsylvania, USA; Tom Mason, Mayo Clinic, USA; Eric Matteson, Mayo Clinic, USA; Jamal Mikdashi, University of Maryland, USA; Emile Mohler, University of Pennsylvania, USA; Paul Monach, Boston University, USA; Brian Rice, University of Pennsylvania, USA; Aditya Sharma, University of Virginia, USA; Antoine Sreih, University of Pennsylvania, USA; John Stone, Massachusetts General Hospital, USA; Nicholas Tsapatsaris, Lahey Clinic, USA; Alexandra Villa-Forte, Cleveland Clinic, USA; Kenneth Warrington, Mayo Clinic, USA; Yusuf Yazici, New York University, USA; Steven Ytterberg, Mayo Clinic, USA. 